\title{
A structural analysis of common and bizarre visual mediators
}

\author{
PHILIP H. MARSHALL, KATHY L. NAU, and CYNTHIA K. CHANDLER \\ Texas Tech University, Lubbock, Texas 79409
}

\begin{abstract}
Recent evidence from the areas of both verbal and visual mediation suggests that qualitative differences exist among mediators. Subjects in this study were asked to generate and describe visual images of common or bizarre interactions for noun pairs that were then judged on the type and number of operations used to form the visual images. Bizarre imagery instructions resulted in images that were generated by the use of significantly more operations and a greater variety of operation combinations than images formed under common imagery instructions.
\end{abstract}

It has been well established that mental images can be used effectively as nonverbal mediators in paired associate situations (Bower, 1970; Bugelski, 1970; Bugelski, Kidd, \& Segmen, 1968; McNulty, 1966; Paivio \& Yuille, 1967; Wood, 1967).

Research has been directed toward identifying the characteristics or attributes of the imaginal process that make imagery an effective mnemonic device in paired associate learning paradigms.

One aspect of the association process that has received some attention is the bizarreness of the images generated to link paired items. For years professional mnemonists have claimed that memory is best facilitated when bizarre images are used (Paivio, 1969). However, the results of research on the mnemonic effectiveness of bizarre imagery have been less than consistent. Andreoff and Yarmey (1976), Delin (1968), and Webber and Marshall (1978) all found better recall performance with bizarre imagery, while other studies reported equal or poorer recall performance than subjects instructed to imagine common associative scenes (Collyer, Jonides, \& Bevan, 1972; Hauck, Walsh, \& Kroll, 1976; Kulhavy \& Heinen, 1974; Nappe \& Wollen, 1973; Senter \& Hoffman, 1976; Wollen, Weber, \& Lowry, 1972).

One possible explanation for the paradox is that mnemonists use more effective strategies than do experimental subjects when forming bizarre images. Although this hypothesis has not been specifically investigated, the possibility becomes more credible when it is recognized that evidence from the areas of both verbal and visual mediation suggests that qualitative differences do exist among mediators.

In the area of verbal mediation, paired associate studies have been conducted that show that differences occur in respect to the complexity and type of

These data were included in a presentation at the meeting of the Southwestern Psychological Association in New Orleans, April 1978. Reprint requests should be sent to Philip H. Marshall, Department of Psychology, Texas Tech University, Lubbock, Texas 79409. transformations used to form verbal mediators, and that these differences are related to recall performance (Bugelski, 1962; Martin, Boersma, \& Cox, 1965). The most ambitious attempt to develop an objective classification system was reported by Prytulak (1971), who used CVCs as stimuli and found that transformations from the to-be-remembered items to the natural language mediators involved various types and numbers of operations. Furthermore, a hierarchy of transformations existed such that some natural language mediatcrs were easier to decode than others and subsequently led to more efficient response recall.

Since the usefulness of both verbal and imagery mediation techniques is thought to derive from their effectiveness in bringing the to-be-remembered items into an integrated meaningful relationship or in reducing interference by making items more unique (Paivio, 1969), it might be postulated that instructions to form mental images connecting words of a paired associate item might result in image-formation processes that could be likened to the transformation processes described by Prytulak (1971). The purpose of the present study was, first, to determine if there are identifiable transformations that are used to transform noun pairs into mental images and, second, to ascertain if images formed under common imagery instructions differ quantitatively and qualitatively from images formed under bizarre imagery instructions.

\section{METHOD}

\section{Subjects}

Subjects were 36 undergraduates who participated to fulfill a requirement for an introductory psychology course.

\section{Materials}

The stimuli were 46 noun pairs selected from the Wood (1967) list, which is made up of relatively high-frequency concrete nouns. The pairs were presented via a Kodak $850 \mathrm{H}$ Carousel projector with one noun appearing directly above the other. 
Table 1

Categories of Operations

\begin{tabular}{|c|c|c|c|}
\hline $\begin{array}{l}\text { Oper- } \\
\text { ation }\end{array}$ & $\begin{array}{c}\text { Example Noun } \\
\text { Pair } \\
\end{array}$ & Definition & Example \\
\hline A & canary-buckle & Simple interaction. & The canary landed on the buckle. \\
\hline B & hailstone-barn & Animation (abnormal movement or interaction). & The hailstone crushed the barn when it fell \\
\hline $\mathrm{C}$ & whistle-snail & Addition of an object. & The boy dropped the whistle on the snail. \\
\hline D & skull-train & Change in the size of one object. & The train went through the huge skull. \\
\hline $\mathrm{E}$ & hairpin-lantern & Change in the function of one object. & The lantern was lit with a hairpin. \\
\hline $\mathrm{F}$ & kitten-wheel & Incorporation of one object as the feature of the other. & The spokes of the wheel were kittens. \\
\hline G & mouse-tobacco & Giving human features or living features. & The mouse spit tobacco in the spitoon. \\
\hline $\mathbf{H}$ & dime-brick & Convergence of the two objects into one. & The brick was made of dimes. \\
\hline
\end{tabular}

\section{Design and Procedure}

Each subject served under both common and bizarre imagery instructions. The students were told that the experimenter was collecting common and bizarre images for use in a later study. Each noun pair was projected on a screen and pronounced by the experimenter to avoid reading errors. The subjects were then asked to mentally visualize an interaction between the nouns of each pair and to write down a detailed description of the image. Each noun-noun pair was presented one time, and all subjects generated and described both a common and a bizarre imaginal interaction for each pair. A period of $60 \mathrm{sec}$ was allowed for the formation and description of each of the interactions. The order in which the imagery instructions were given (i.e., to generate either a common or a bizarre image first) was counterbalanced across subjects.

\section{Scoring}

Two independent judges determined if subjects had followed directions by deciding if the verbal descriptions could actually be imagined mentally. Those descriptions that were judged as meeting this criterion were then scored by the two judges according to eight transformations developed as possible methods to be used to dimensionalize the visual images. In order to establish this classification system, 10 individuals were previously asked to generate and describe common and bizarre interactive images for 10 noun pairs. From these written descriptions, the types of transformations used to generate the visual images were determined. The categories (listed in Table 1, along with an example of each), although not an exhaustive list of possible operations, are representative of all the transformations used to describe the 200 generated images. In judging, it was emphasized that an individual transformation could be used more than once in the formation of a single image. For example, one response given to the noun pair "trainskull" was, "The engineer drove the train down the tracks which went in to the huge skull." The response was given a score of C-C-D. The subject added two objects (tracks and engineer) and changed the normal size of one of the stimulus objects (huge skull) in forming the image.

\section{RESULTS AND DISCUSSION}

Of the 1,656 responses possible under each instruction condition, the judges were unable to reach agreement in regard to the types of transformations used to generate the image, decided that the description could not be mentally imagined, or decided that the description did not involve an interactive association for 247 of the bizarre images and 261 of the common images. Consequently, only data for $85 \%$ of the descrip- tions generated under the bizarre imagery instructions and $84 \%$ of the common-instruction images were used in the analyses reported below.

The mean number of transformations used by subjects under common imagery instructions was 1.06 and 1.53 under bizarre imagery instructions. This difference was significant $[\mathrm{t}(35)=2.238, \mathrm{p}<.05]$. As shown in Table 2, when subjects were asked to form common images to connect the noun pairs, they used predominantly only one transformation. When the same subjects were asked to link the nouns by using bizarre images, they used one or two transformations. The use of three or more transformations was quite uncommon under both instruction conditions.

It was found that 53 different transformations or combinations of transformations were used totally to generate images in the bizarre condition, while only 15 combinations were used under common instructions. The common images described connected the object pairs by using simple interaction or by the addition of an object, while the most commonly used strategies for generating images under bizarre instructions were to give human features and movement to an inanimate object or to make one of the objects a feature of the other. Table 3 summarizes the combinations of transformations that account for at least $78 \%$ of the data in each condition.

The results of this study indicate that there are identifiable transformations that are used by subjects instructed to link noun pairs by imagery. It was further found that variations in instructions affect the number and types of transformations. A relationship between

Table 2

Percent of Usage of Multiple Transformations

\begin{tabular}{crr}
\hline Transformations* & Common & Bizarre \\
\hline 1 & 97.42 & 55.90 \\
2 & 2.30 & 26.70 \\
3 & .28 & 6.70 \\
4 & .00 & .60 \\
5 & .00 & .10 \\
6 & .00 & .00 \\
\hline
\end{tabular}

*Number of transformations in image. 
Table 3

Percent Usage of Different Types of Transformations in Each Condition

\begin{tabular}{ccc}
\hline $\begin{array}{c}\text { Specific } \\
\text { Operation }\end{array}$ & Common & Bizarre \\
\hline A & 59 & 6 \\
B & & 8 \\
C & 31 & 3 \\
D & & 4 \\
E & & 6 \\
F & 15 \\
G & 10 \\
B-G & 15 \\
B-C & 4 \\
D-G & 3 \\
B-D & 2 \\
B-C-G & 2 \\
\hline
\end{tabular}

verbal mediator complexity and recall has already been found (Prytulak, 1971), and it would also be of interest to determine if a relationship exists between image complexity scores and recall performance.

\section{REFERENCES}

Andreoff, G. R., \& YARmey, D. Bizarre imagery and association learning: A confirmation. Perceptual and Motor Skills, 1976, 43, 143-148.

BowER, G. H. Imagery as a relational organizer in associative learning. Journal of Verbal Learning and Verbal Behavior, 1970, 9, 529-533.

BugELSKI, B. R. Presentation time, total time, and mediation in paired-associate learning. Journal of Experimental Psychology, 1962, 63, 409-412.

Bugelski, B. R. Words and things and images. American Psychologist, 1970, 25, 1002-1012.

Bugelski, B. R., Kidd, E., \& Segmen, J. Image as a mediator in one-trial paired-associate learning. Journal of Experimental Psychology, 1968, 76, 69-73.
Collyer, S. C., Jonides, J., \& Bevan, W. Images as memory aids: Is bizarreness helpful? American Journal of Psychology, 1972, 88, 31-38.

DELiN, P. S. Success in recall as a function of success in implementation of mnemonic instructions. Psychonomic Science, 1968, 12, 153-154.

Hauck, P. D., Walsh, C. C., \& Kroll, N. E. A. Visual imagery mnemonics: Common vs. bizarre mental images. Bulletin of the Psychonomic Society, 1976, 7, 160-162.

Kulhavy, R. W., \& Heinen, J. R. K. Imaginal attributes in learning sentence embedded noun pairs. Psychological Reports, 1974, 34, 487-490.

Martin, C. J., Boersma, F. J., \& Cox, D. L. A classification of associative strategies in paired-associate learning. Psychonomic Science, 1965, 3, 455-456.

McNulty, J. A. The effects of "instructions to mediate" upon paired-associate learning. Psychonomic Science, 1966, 4, 61-62.

NAPPE, G. W., \& Wollen, K. A. Effects of instruction to form common and bizarre mental images on retention. Journal of Experimental Psychology, 1973, 100, 6-8.

Paivio, A. Mental imagery in associative learning and memory. Psychological Review, 1969, 76, 241-263.

Paivio, A., \& Yuille, J. C. Mediation instructions and word attributes in paired-associated learning. Psychonomic Science, 1967, 8, 65-66.

PrYtulak, L. S. Natural language mediation. Cognitive Psychology, 1971, 2, 1-56.

Senter, R. J., \& Hoffman, R. R. Bizarreness as a nonessential variable in mnemonic imagery: A confirmation. Bulletin of the Psychonomic Society, 1976, 7, 163-164.

Webber, S. M., \& Marshall, P. H. Bizarreness effects in imagery as a function of processing level and delay. Journal of Mental Imagery, 1978, 2, 291-300.

Wollen, K. A., Weber, A., \& Lowry, D. H. Bizarreness versus interaction of mental images as determinants of learning. Cognitive Psychology, 1972, 3, 518-523.

WooD, G. Mnemonic systems in recall. Journal of Educational Psychology, 1967, 58(6, Part 2), 1-27.

(Received for publication April 19, 1979.) 